\title{
ON THE TOTAL $k$-DOMINATION IN GRAPHS
}

\author{
Sergio Bermudo \\ Department of Economics \\ Quantitative Methods and Economic History \\ Universidad Pablo de Olavide, ES-41013 Seville, Spain \\ e-mail: sbernav@upo.es \\ JuAn C. HeRnÁNDEZ-Gómez \\ AND \\ José M. SigarReta \\ Faculty of Mathematics \\ Autonomous University of Guerrero \\ Carlos E. Adame 5, Col. La Garita, Acapulco, Guerrero, Mexico \\ e-mail: jcarloshg@gmail.com \\ josemariasigarretaalmira@hotmail.com
}

\begin{abstract}
Let $G=(V, E)$ be a graph; a set $S \subseteq V$ is a total $k$-dominating set if every vertex $v \in V$ has at least $k$ neighbors in $S$. The total $k$-domination number $\gamma_{k t}(G)$ is the minimum cardinality among all total $k$-dominating sets. In this paper we obtain several tight bounds for the total $k$-domination number of a graph. In particular, we investigate the relationship between the total $k$-domination number of a graph and the order, the size, the girth, the minimum and maximum degree, the diameter, and other domination parameters of the graph.
\end{abstract}

Keywords: $k$-domination, total $k$-domination, $k$-tuple domination, $k$-tuple total domination.

2010 Mathematics Subject Classification: 05C69.

\section{REFERENCES}

[1] S. Bermudo, J.L. Sánchez and J.M. Sigarreta, Total k-domination in Cartesian product graphs, Period. Math. Hungar. (2016), to appear. 
[2] S. Bermudo, D.L. Jalemskaya and J.M. Sigarreta, Total 2-domination in grid graphs, Util. Math. (2017), to appear.

[3] E.J. Cockayne and A.G. Thomason, An upper bound for the k-tuple domination number, J. Combin. Math. Combin. Comput. 64 (2008) 251-254.

[4] P. Dorbec, S. Gravier, S. Klavžar and S. Špacapan, Some results on total domination in direct products of graphs, Discuss. Math. Graph Theory 26 (2006) 103-112. doi:10.7151/dmgt.1305

[5] O. Favaron, M.A. Henning, J. Puech and D. Rautenbach, On domination and annihilation in graphs with claw-free blocks, Discrete Math. 231 (2001) 143-151. doi:10.1016/S0012-365X(00)00313-7

[6] H. Fernau, J.A. Rodríguez-Velázquez and J.M. Sigarreta, Global powerful r-alliances and total k-domination in graphs, Util. Math. 98 (2015) 127-147.

[7] J. Harant and M.A. Henning, On double domination in graphs, Discuss. Math. Graph Theory 25 (2005) 29-34. doi:10.7151/dmgt.1256

[8] F. Harary and T.W. Haynes, Double domination in graphs, Ars Combin. 55 (2000) 201-213.

[9] T.W. Haynes, S.T. Hedetniemi and P.J. Slater, Fundamentals of Domination in Graphs (Marcel Dekker, Inc., New York, 1998).

[10] T.W. Haynes, S.T. Hedetniemi and P.J. Slater, Domination in Graphs: Advanced Topics (Marcel Dekker, Inc., New York, 1998).

[11] M.A. Henning, A survey of selected recent results on total domination in graphs, Discrete Math. 309 (2009) 32-63. doi:10.1016/j.disc.2007.12.044

[12] M.A. Henning and A.P. Kazemi, $k$-tuple total domination in graphs, Discrete Appl. Math. 158 (2010) 1006-1011. doi:10.1016/j.dam.2010.01.009

[13] M.A. Henning and A.P. Kazemi, $k$-tuple total domination in cross products of graphs, J. Comb. Optim. 24 (2012) 339-346. doi:10.1007/s10878-011-9389-z

[14] M.A. Henning and A. Yeo, Total Domination in Graphs (Springer Monographs in Mathematics, 2013).

[15] A.P. Kazemi, On the total k-domination number of graphs, Discuss. Math. Graph Theory 32 (2012) 419-426. doi:10.7151/dmgt.1616

[16] A. Klobucar, Total domination numbers of Cartesian products, Math. Commun. 9 (2004) $35-44$.

[17] V.R. Kulli, On n-total domination number in graphs, Graph theory, Combinatorics, Algorithms, and Applications (San Francisco, CA, 1989), (SIAM, Philadelphia, PA, 1991) 319-324. 
Received 21 April 2016

Revised 21 December 2016

Accepted 21 December 2016 